\title{
Multicriteria decision analysis (MCDA) in health care: a systematic review of the main characteristics and methodological steps
}

\author{
Talita D. C. Frazão* (D), Deyse G. G. Camilo, Eric L. S. Cabral and Ricardo P. Souza
}

\begin{abstract}
Background: The health area is one of the most affected systems on the perspective of decision-making with multiobjectives, thus becoming prone to errors in the final solution, however, multicriteria decision analysis (MDCA) appears as an aid tool for this process decision-making. Therefore,the present study aims to analyze and synthesize articles found in the literature, involing MCDA in health care, evaluating general issues and methodological aspects, structuring them in a single work.

Methods: Surveys in the bibliographic databases SCOPUS and PUBMED indicated 1852 documents on the subject, however after a careful verificatios, 66 studies were selected to be analyzed completely. The data extracted from the included articles were organized into a spreadsheet for the preparation of analysis, and the technique used was descriptive statistics.

Results: It was possible to identify a growth trend in the application of the MCDA in the health area, but no dominance was identified in relation to the authors of the publication and the periodicals where they are published, but some countries stood out in terms of the number of published researches, such as: Canada and Turkey. In defining the decision problem, and in defining criteria, the "literature" presented the greatest demand for those who wish to structure their decision problem. Finally, it was verified by the analysis of the problem, that the MCDA to solve the problems of ranking has comprehensive application and that there is a greater incidence in the use of the AHP and Logic methods Fuzzy.

Conclusion: With this, it is possible to observe, through the data of this review, that more than the multicriteria methods, the multicriteria decision model has been highlighted, also in the health area. In addition, the study can guide new applications and techniques using MCDA in the health care.
\end{abstract}

Keywords: Multicriteria decision analysis, Health care, Systematic review, Methodological aspects

\section{Background}

The issue of multiple objectives is always present in the problems within organizations; Increasing the complexity of decisions. In this setting, it is necessary to find techniques that include in the decision-making process, the greatest number of criteria that guide and influence decisions, in order to reduce errors. However, most of the time this procedure is not easy to perform, since in many situations, the criteria for decision making are

*Correspondence: thalytachaggas@ufrn.edu.br

Departamento de Engenharia de Produção, Centro de Tecnologia,

Universidade Federal do Rio Grande do Norte, 59072-970 Natal, Brazil conflicting, increasing the level of uncertainty of the final response [1-3].

In order to increase the reliability and credibility of the chosen solution, decision support methodologies, such as Multicriteria Decision Support Methods (MCDA), have emerged [4,5]. These methods are intended to assist in the decision-making process, in order to minimize the responsibility of the final decision-maker, and to guarantee a solution in accordance with the criteria in question [6].

In the health area, these procedures are even more complex, since they involve not only technical or economic issues, but also the human factor, causing conflicts of

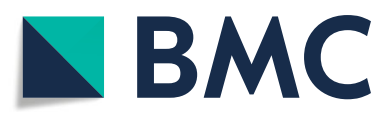

(c) The Author(s). 2018 Open Access This article is distributed under the terms of the Creative Commons Attribution 4.0 International License (http://creativecommons.org/licenses/by/4.0/), which permits unrestricted use, distribution, and reproduction in any medium, provided you give appropriate credit to the original author(s) and the source, provide a link to the Creative Commons license, and indicate if changes were made. The Creative Commons Public Domain Dedication waiver (http://creativecommons.org/publicdomain/zero/1.0/) applies to the data made available in this article, unless otherwise stated. 
interest and hindering the final decision [2]. Therefore, many studies, using MCDA, are carried out with the aim of optimizing health systems as a whole [7-10].

Some studies have been concerned with analyzing a specific application sector, such as the evaluation of health technology [11]. Others depart for a more humane view, evaluating studies aimed at assessing patient preference [12]. And there are those who go further, and aim to know and analyze the MCDA in a complete way in health $[13,14]$.

As there are a great number of studies involving MCDA in the health area, this study aims to analyze and synthesize the information found in the literature, by evaluating general questions and methodological aspects, structuring in a single work the main articles.

For this, it was developed in a systematic revision model, which is subdivided into two stages of evaluation. First the analysis of the general questions of the article, aiming to know and evaluate the scenario of the MCDA studies in the health care. The second stage will be the structural analysis of the research.

\section{Conceptualization of the MCDA}

There is a multicriteria decision problem, when Decision Maker (DM) faces a situation with at least two alternatives of action with conflicting objectives among which it must choose $[15,16]$. These decisions are rarely made by a single individual, even if the responsibility for the decision rests on a well-identified DM, the decision will usually be the product of an interaction between that individual's preferences and those of other actors or stakeholders [17]. In addition to DM, there may still be: the Analyst (provides methodological support for the decision process); the Client (an intermediary between the DM and the Analyst) and the Specialist (a professional who knows the mechanisms of behavior of the object of study) [17].

The construction of models and the choice of methods are directly linked to the actors of the decision-making process. The meaning of the decision-making expressions and decision support method may vary in the literature $[18,19]$. In the present research, it is considered that a multicriteria decision model is a formal representation and with simplification of the decision problem with multiple objectives faced by the DM, already a method of support the multicriteria decision is a methodological formulation or a theory, with axiomatic structure well-defined, which can be used to construct a decision model [15].

In problems that use the multicriteria decision model, there is a need to obtain the alternatives, criteria, weights, decision matrix and scale. According to Dolan [20], Baltussen et al. [21], Belton and Stewart [22]: An alternative is a course of action assessed through a decision-making process; The criteria are the performance measures, by which, the options will be judged and carefully selected to ensure integrity, viability and mutual independence, avoiding redundancy and an excessive number of criteria; As for weight, it is a number that expresses the relative importance of the criteria against which alternatives are compared; a decision matrix is a table that presents the performance of each alternative according to the criteria and is measured at appropriate scales; The decision matrix is used inversely with the terms performance matrix; Finally, the term scale refers to an instrument, in which the performance of an alternative is measured. Two types of data can be measured on these scales, in particular, qualitative and quantitative scales.

\section{Stages of the multicriteria decision model}

For this study, it was considered the structure proposed by Diaby and Goeree [23], which consists of three stages: (I) Define the limits of the problem - The study must have a well elaborated and explicit objective, where a central problem must be pre-definined, thus serving as a guide to the study itself; (II) Identify the evaluation criteria - The next step is to select the criteria for the analysis of the research, ie, which criteria will be used to evaluate the problem under study; (III) Select a multicriteria model - After completing the application methodology, one must select the model to be used in the study, this model must be selected considering the problem defined in step I.

Considering that, the problem has been defined clearly and the criteria to assist in decision-making are pointed out, then a multi-criteria evaluation model can be chosen in order to meet the conditions and needs of the problem of interest [20]. Roy [17] addresses four types of problems: (I) Choice - it is the selection of a subset as small as possible, so that a single action can eventually be chosen; (II) Sorting - is the classification that leads to an assignment of each action to a category, where categories are defined as an advantage according to certain norms that deal with the final destination of the actions that will be assigned to them; (III) Ranking - is a ordination, which is obtained by placing all actions, or simply the "most attractive ones", in equivalences that are totally or partially ordered according to preferences; (IV) Description - is the development of a description of actions and their consequences in appropriate terms.

Diaby and Goeree [23] further conclude that for each type of problem, there are appropriate MCDA methods.

It is of interest of this research only the three problematic issues, because the main objective is accomplished in the analysis of articles, which present the resolution of problems through a choice, a sorting procedure, or still resulting in a rank of the evaluated alternatives. 


\section{Methods}

\section{General search data}

The review of the literature presented in this study is based on bibliographic databases SCOPUS and PUBMED, including MEDLINE, PMC (PubMed Central) e NCBI Bookshelf, which were searched in March 2017. No language, publication date, or publication status restrictions were imposed to reach as many articles as possible. The consideration of two data repositories seeks to avoid a possible bias and/or omission in the final set of selected articles. To control the quality of published works, research was limited to journals.

The survey included articles that have MCDA application in health care. Thus, it is possible to investigate how and for what purpose the researchers and practitioners use MCDA to aid decision making in health care.

In the SCOPUS repository the searches were given for "title, abstract and keywords", the added filters are presented in Fig. 1. The data extracted from the articles selected were: Author; Date of the survey; Location (Country where the survey was conducted, if not reported the country of origin of the main author); Periodical of publication; Title of study; Type of intervention (according to its characteristics were classified into six classes); Type of problem (choice, ranking and sorting). How did the problem arise? (How happened definition of the problem?) (According to their characteristics were classified into five classes); How did the definition of the criteria occur? (According to their characteristics were classified into five classes); and what is the weighting method used?

Table 1 summarizes the main features of the studies included in the review.

\section{Search steps and search criteria}

The study was performed in four stages, as shown in Fig. 1, obeying some inclusion and exclusion criteria, as shown in Table 2. The research was performed independently in an unblinded standardized manner by two reviewers. Agreements between reviewers were resolved by consensus. We developed a data extraction sheet (based on the what we want to extract from the articles). The articles were divided between two authors for data extraction. Already, disagreements were resolved by discussion between two review authors; if no agreement could be reached, it a third author would decide. The steps and their respective criteria are described below:

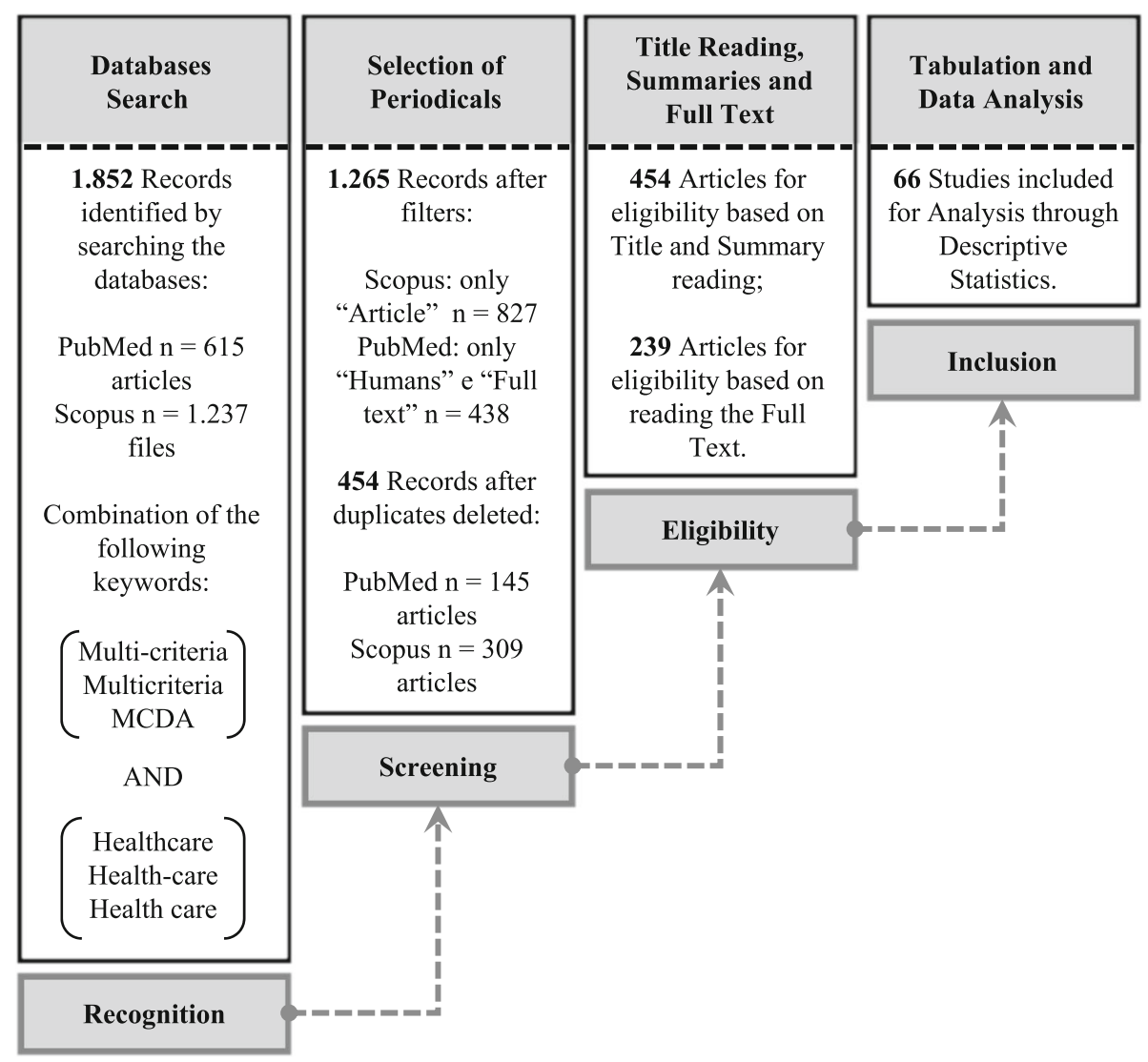

Fig. 1 Sequential steps which were followed for the collection and analysis of the data of the included articles 


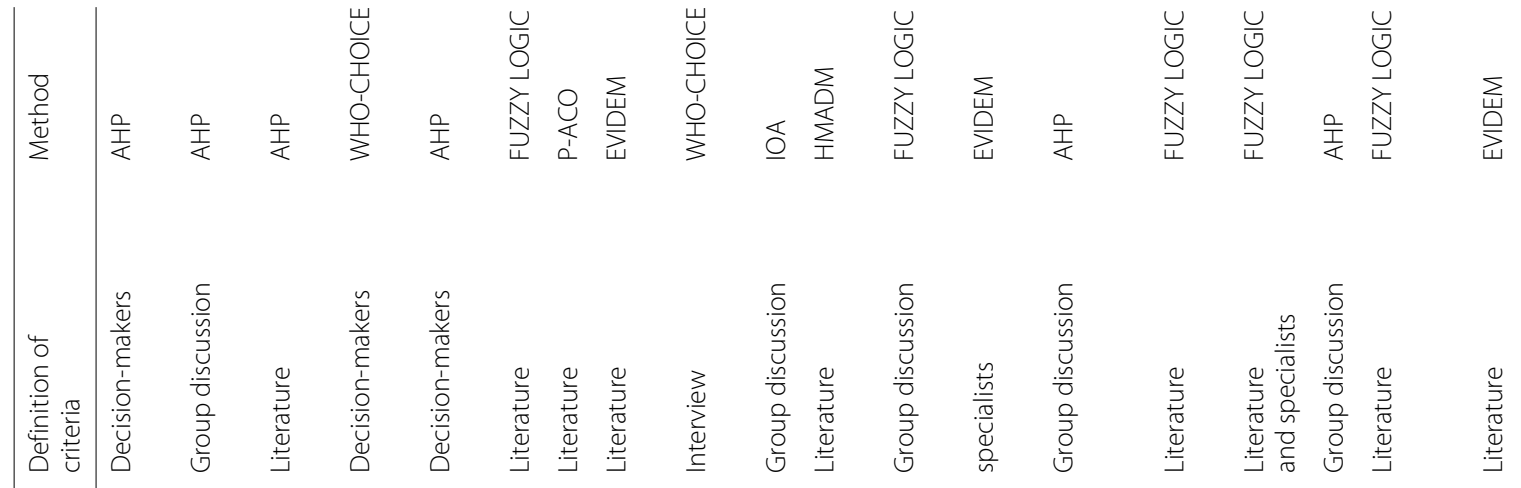

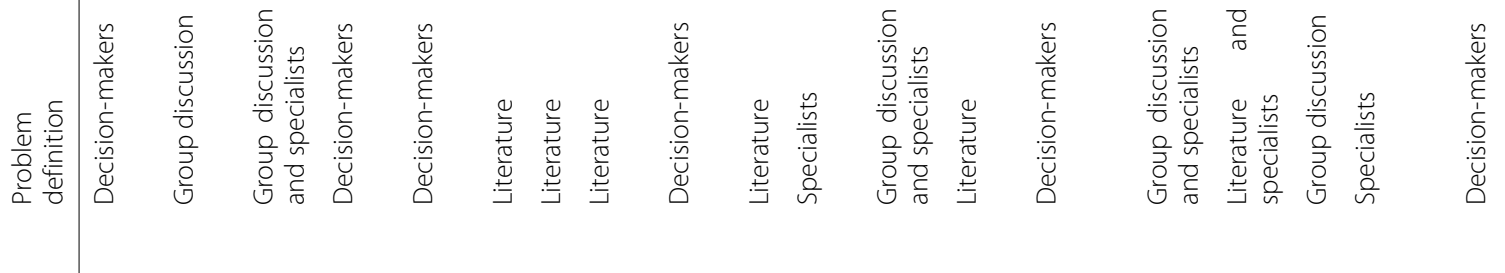

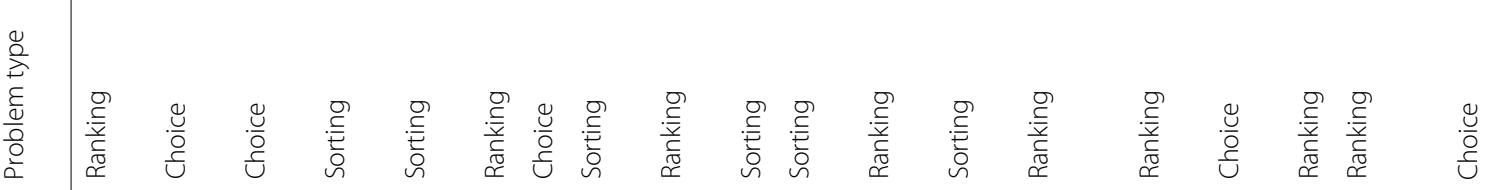

$$
\begin{aligned}
& \text { MIIMUn }
\end{aligned}
$$

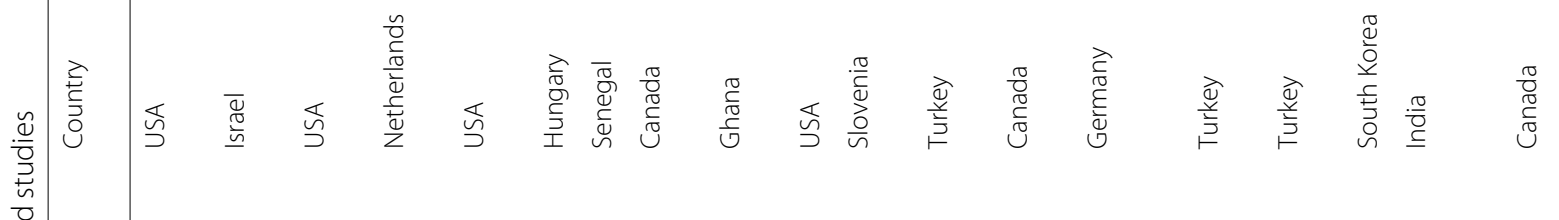

$$
\begin{aligned}
& \frac{0}{\frac{0}{0}}
\end{aligned}
$$

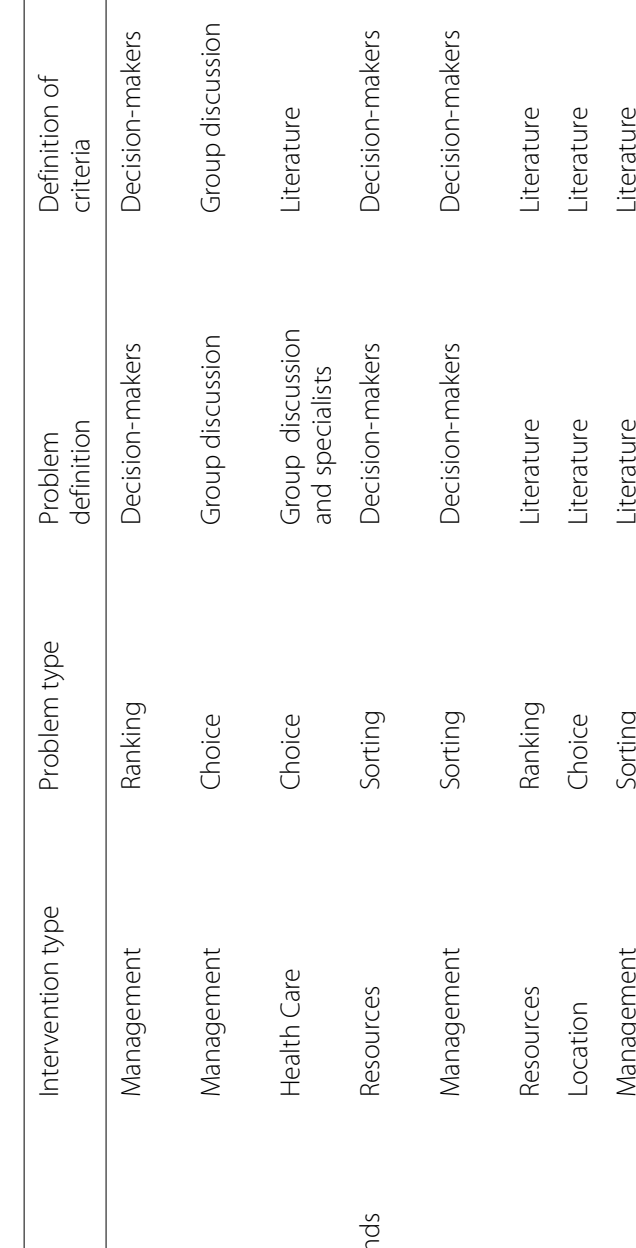

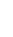




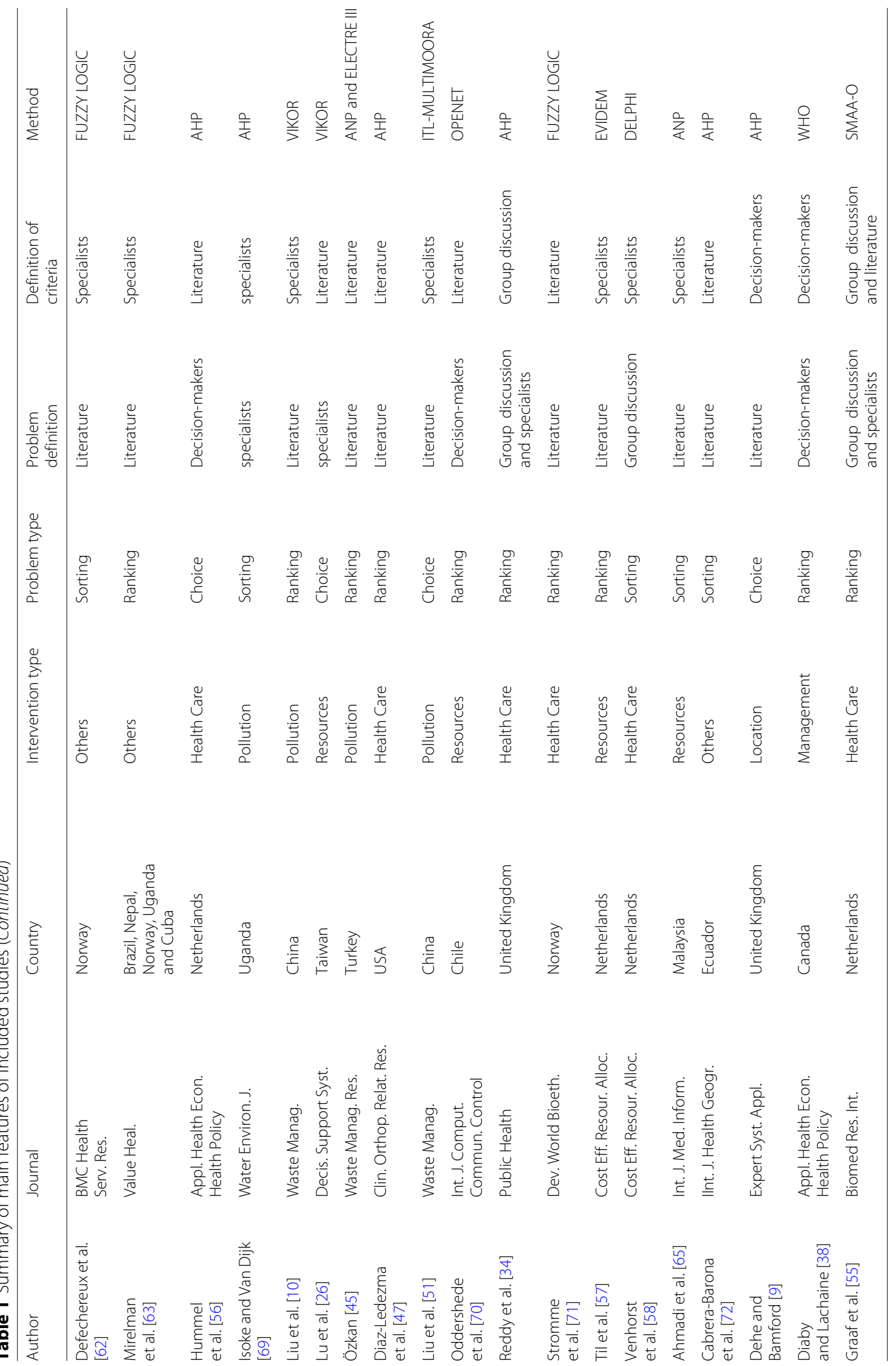




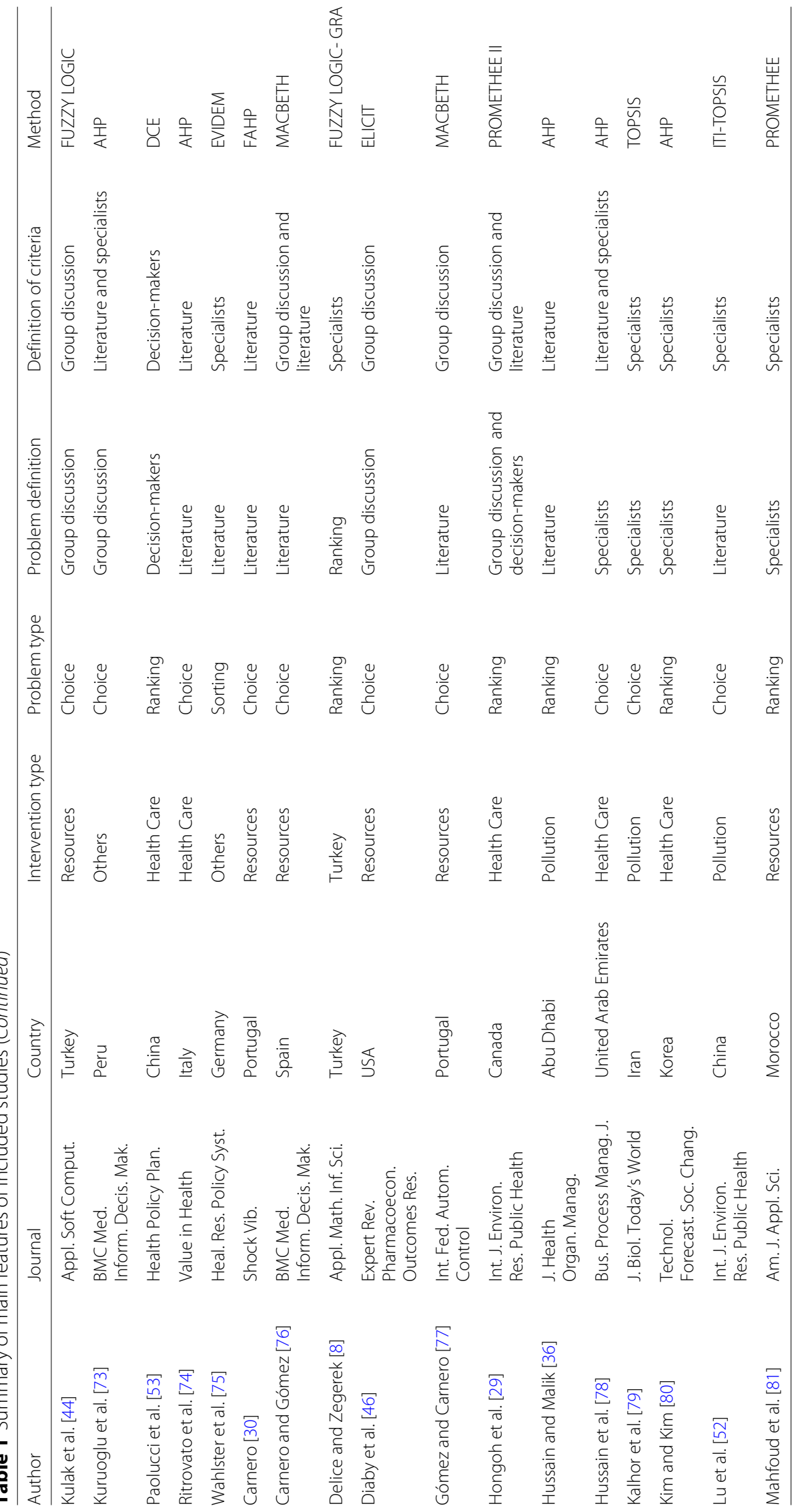




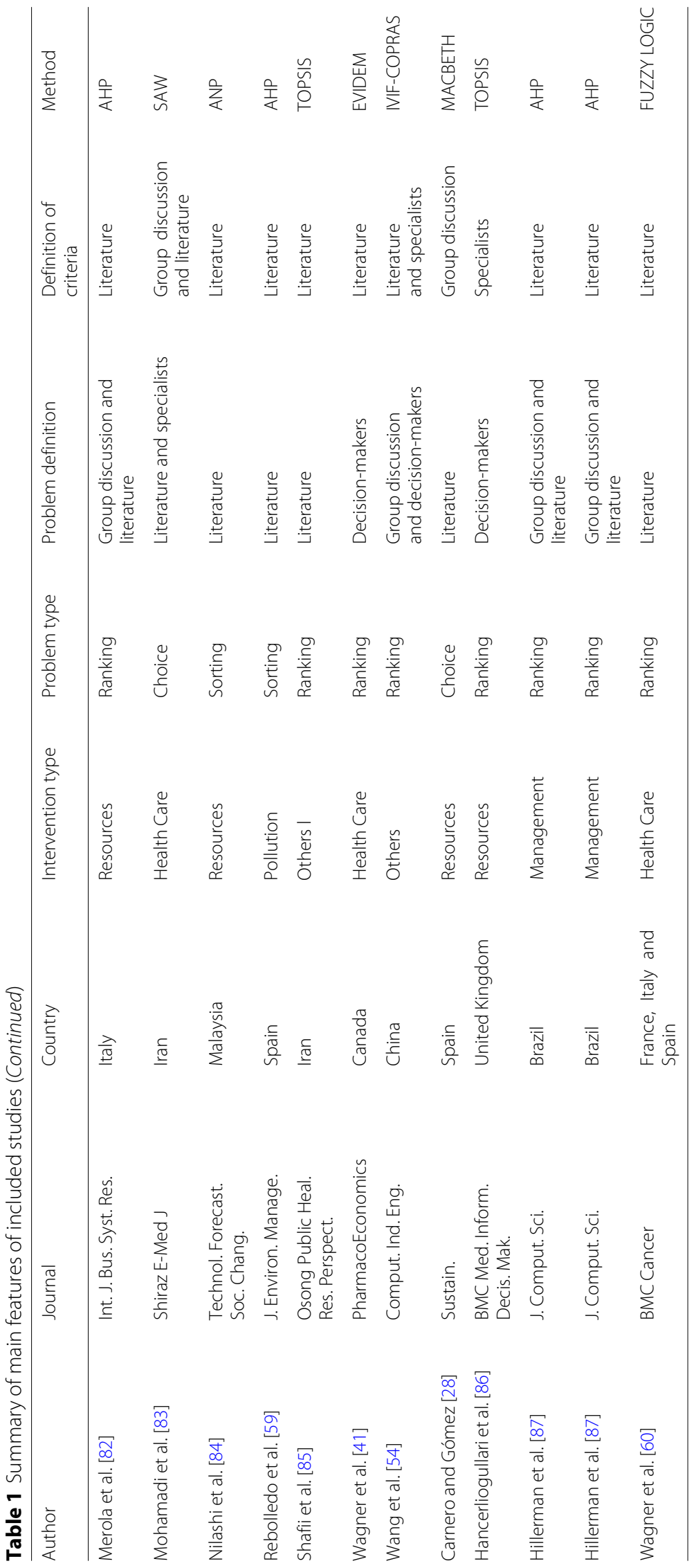


Table 2 Criteria used for inclusion and exclusion of the studies in the review

\author{
Inclusion criteria \\ Inclusion criteria for title and abstract \\ Is a health intervention aided by the MCDA.

\section{Exclusion criteria} \\ Exclusion criteria for title and abstract \\ Does not present abstract; Does not present the full text available; \\ Be a review article; Does not be an MCDA application and / nor Does; \\ Not be MCDA application in the health area.
}

\section{Inclusion criteria for full text}

The MCDA is structured according to the steps proposed by Diaby and Goeree (2014); Provide the necessary information for analysis of general data and methodological steps.

\section{Full text exclusion criteria}

Be an MCDA application, however: Does not follow the steps outlined above; Does not make clear the structuring of the problem; Does not make clear the criteria and their origin; Does not present decision matrix; Does not present the quantitative weighting of the criteria; Presents a purely mathematical model.
(I) Identification Nine words combinations were searched for in title, abstract and keywords fields. This words were: Multi-criteria and Healthcare; Multi-criteria and Health-care; Multi-criteria and Health care; Multicriteria and Healthcare; Multicriteria and Health-care; Multicriteria and Health care; MCDA and Health-care; MCDA and Healthcare; MCDA and Health care. The use of these combinations is justified by the need to restrict the search of articles relevant to research, and because there is a variation of the terms in the literature. Figure 1 shows the amount of documents resulting after the execution of each of the procedures.

(II) Screening For the first selection of studies, filters were applied and duplicate documents removed;

(III) Eligibility After the elimination of duplicate articles, a title, abstract and full text were read. This stage of eligibility consisted of two phases. In the first, the titles and abstracts were read, obeying an inclusion criterion (Table 2). If they answered the prerequisite, the full text would be downloaded. For the second phase, which was the reading of the articles, pre-selected and downloaded, two inclusion criteria and seven exclusion criteria were determined (Table 2);

(IV) Inclusion The data extracted from the included articles were organized into a spreadsheet for the preparation of analysis, and the technique used was descriptive statistics. The results are presented and discussed in "Results" section.

\section{Results}

\section{Analysis of the general aspects}

Amount of 1852 publications were identified in the databases by the combination of keywords. After a refined search (Scopus: only, "Article" $n=827$, PubMed: only, "Humans" e "Full text" $n=438$ ) and after adjusting for duplicates 454 remained. Of these, 239 studies were discarded because after reviewing the abstracts it appeared that these papers clearly did not meet the criteria. The full text of the remaining 239 articles was examined in more detail. It appeared that 173 studies did not meet the inclusion criteria as described (Fig. 7). Sixty-six studies met the inclusion criteria and were included in the review (See flow diagram Fig. 1).

Within the line of general analysis of the studies selected for analysis, it is sought to identify the line of growth or decrease of research in the area, in addition to diagnosing the main authors and journals, and the countries that publish the most over time. The analyzed data are shown in Fig. 2.

Figure $2 \mathrm{a}$ shows the number of subject publications per year. It is evidenced a growth of publications on the MCDA theme in health, with great emphasis from the year 2014.

Figure $2 \mathrm{~b}$ addresses the location of study application and / or origin of the main authors of the articles selected in the study. We took into account the inclusion criteria for full text (see Table 2). Thus the countries Canada, Turkey and the USA lead in quantity of publications on the subject, each with 6 articles. In this way, we can affirm that their studies supported the structured methodology of the MCDA, which were the focus of this research.

Throughout the review, thirty-three countries were surveyed (Table 1 ), however, only those who had more than one total publication were included in the analysis.

Figure 2c demonstrates the authors who stand out most in the theme. We can visualize the seven authors who had more than one publication among the analyzed studies, and it is possible to say in front of the graph that there is no author who stands out from the others, since Dursun, with three publications in all, is followed by plus six authors with two publications each. 

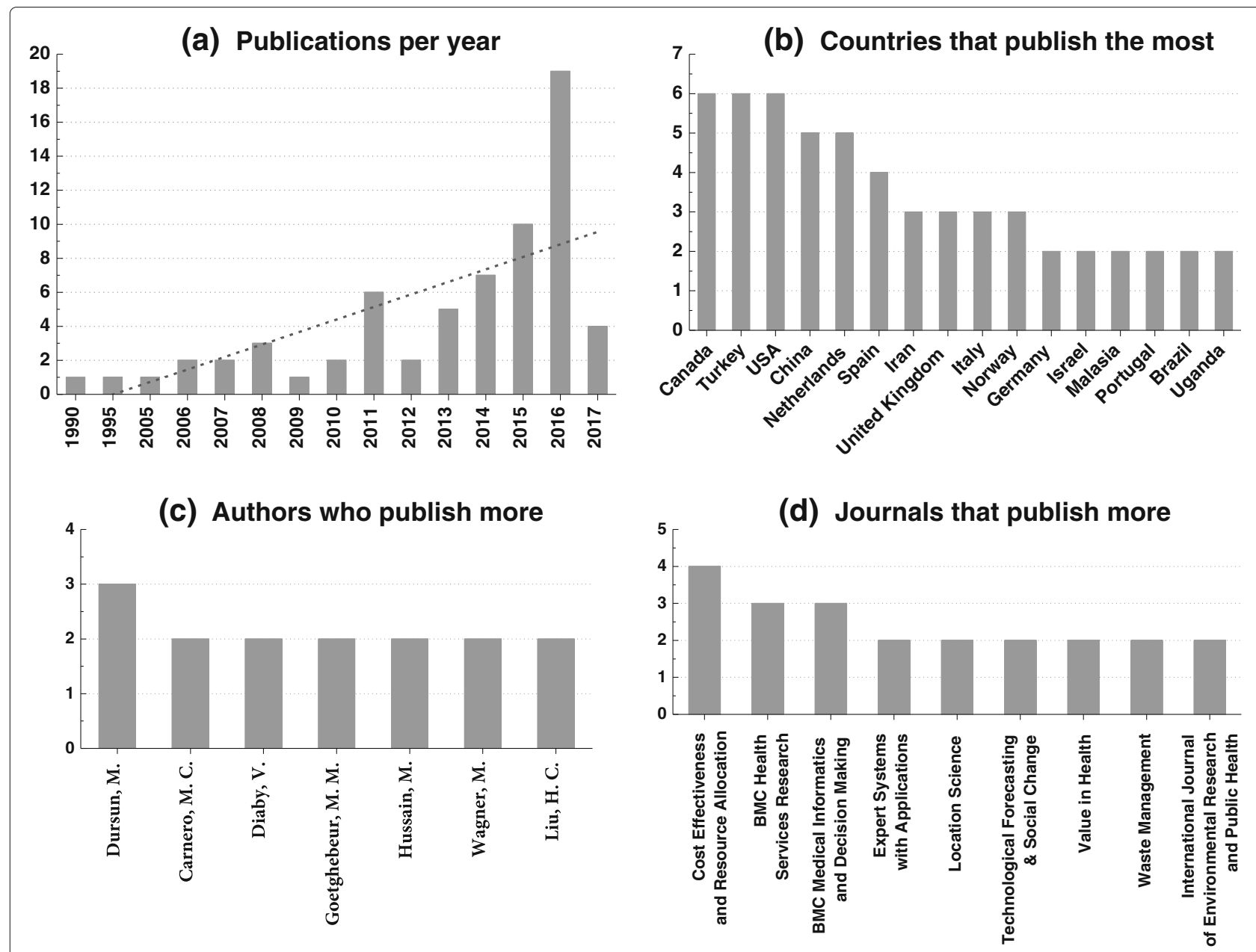

Fig. 2 Four chart which show the analysis of the general aspects of the articles included, such as: a demonstration of publications, $\mathbf{b}$ main countries, c authors, and $\mathbf{d}$ journals

According to Fig. 2d, brings the most published papers on the topic of MCDA in the health area. Eight newspapers stand out, with Cost Effectiveness and Resource Allocation being more prominent with four publications.

Finally, a parameter widely used in the literature to identify and classify the most important works is the number of times it is cited [24]. In Table 3 are presented the twenty most cited papers in relation to 66 selected ones, as well as the number of citations registered in the Scopus database, in June 2018.

Considering the set of articles selected in this study, the articles of Baltussen et al. and Goetghebeur et al. [21, 25] were the most cited; presenting as a solution a better allocation of public health resources. The authors developed this study, aiming to benefit disadvantaged groups, making possible the development of a public health policy, as an example: alternatives were presented that support decision making in the treatment of Turner syndrome; Already Lu et al. [26], elaborated a hybrid model for the adoption of new technologies. On the other hand, Doerner et al. [27] has created a combinatorial optimization formulation to choose the best location for a mobile health center.

\section{Analysis of methodological steps Definition of the decision problem}

In addition to the verification of the general data and presentation of the current scenario of the MCDAs in the health area, this study sought to investigate the methodological structure of the included studies in order to identify the techniques and strategies that researchers, specialists and decision makers are agreeing to use for solve a multicriteria problem in the health area.

To assist researchers and health professionals, this research investigated in the articles included, the following methodological steps: How was the problem established; How did the definition of the criteria occur; The model would be to solve which problem and which 
Table 3 Twenty most cited papers among the 66 selected papers

\begin{tabular}{lll}
\hline Research & Year of publication & Scopus citations \\
\hline Baltussen et al. [21] & 2006 & 265 \\
Goetghebeur et al. [25] & 2008 & 76 \\
Goetghebeur et al. [39] & 2010 & 70 \\
Lu et al. [26] & 2013 & 64 \\
Doerner et al. [27] & 2007 & 63 \\
Dursun et al. [31] & 2010 & 49 \\
Jehu-Appiah et al. [61] & 2008 & 47 \\
Liu et al. [10] & 2013 & 43 \\
Tony et al. [40] & 2011 & 41 \\
Singh et al. [33] & 2006 & 34 \\
Liu et al. [51] & 2014 & 34 \\
Defechereux et al. [62] & 2012 & 33 \\
Kuzma et al. [49] & 2008 & 32 \\
Dolan [48] & 2005 & 30 \\
Dursun et al. [43] & 2011 & 30 \\
Mirelman et al. [63] & 2012 & 26 \\
Sinuany-Stern et al. [64] & 1995 & 23 \\
Til et al. [57] & 2014 & 21 \\
Ahmadi et al. [65] & 2015 & 21 \\
Diaz-Ledezma et al. [47] & 2014 & 17 \\
\hline
\end{tabular}

weighting method was used. Initially we verified the form that the decision problem was based (Fig. 3).

From a total of 66 articles analyzed, it is visualized in Fig. 3 that $47 \%$ of the articles defined the decision problem based on the literature. This represents 31 articles. However, it is important to explain that of these 31 articles, 2 studies added to the literature also consulted experts.

The definition of the problem through discussion groups, formed by interdisciplinary teams, represented $21 \%$ of the articles included. This is equivalent to 14 surveys, among these 2 articles besides the discussion

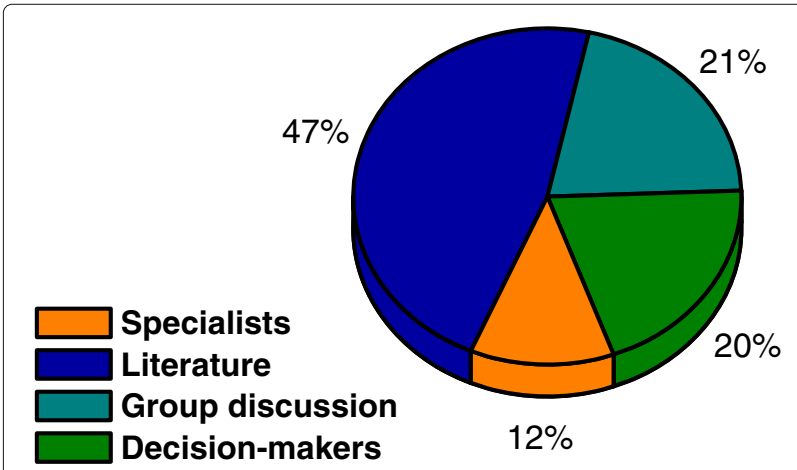

Fig. 3 Analysis of the problem definition strategy for structuring the MCDA group consulted the literature, another 5 in the group discourses asked for support from specialists.

The strategy to define the problem through the knowledge and experience of DMs was attributed to 13 articles analyzed (Fig. 3), which represented $20 \%$ of the included studies. Finally, $12 \%$ of the analyzed articles used the strategy to define the problem by means of experts, and in 2 articles this was done through a pre-defined questionnaire.

Within the limits of the decision problem that are defined, the type of intervention that the MCDA will assist is selected, either by sorting, selecting or even ordering the alternatives (Fig. 4). To delimit the decision problem, it becomes necessary to determine the purpose of the model and with it the type of intervention. This identification will have an influence on the final model, considering that the decision process is found in the initial filters [15].

Of the 66 articles analyzed, 30\% were concerned with helping health care problems, among them, 7 articles deal with the treatment of diseases, 7 articles on the diagnosis of diseases, 3 articles on disease prioritization, and 3 articles on related issues with medicines.

Being that, $25 \%$ of the articles, the intervention was to identify resources. The resources dealt with the choice of information technology in 7 articles, maintenance of equipment in 4 articles, allocation of resources in 3 articles, and choice of equipment in 3 other articles.

On the other hand, $17 \%$ of the articles studied, DMs decide, through the MCDA, questions related to environmental pollution, with 9 articles addressing the choice of treatment and more adequate disposal of hospital waste and 2 articles addressing water pollution.

Besides that, $14 \%$ of the articles studied, it was evidenced the use of MCDA to support management decisions, with 7 articles addressing the theme in hospital management planning, 2 articles addressed the theme in budget prioritization. Another 2 articles, representing 3\% of the total, addressed the theme for choosing the best location for the installation of health facilities.

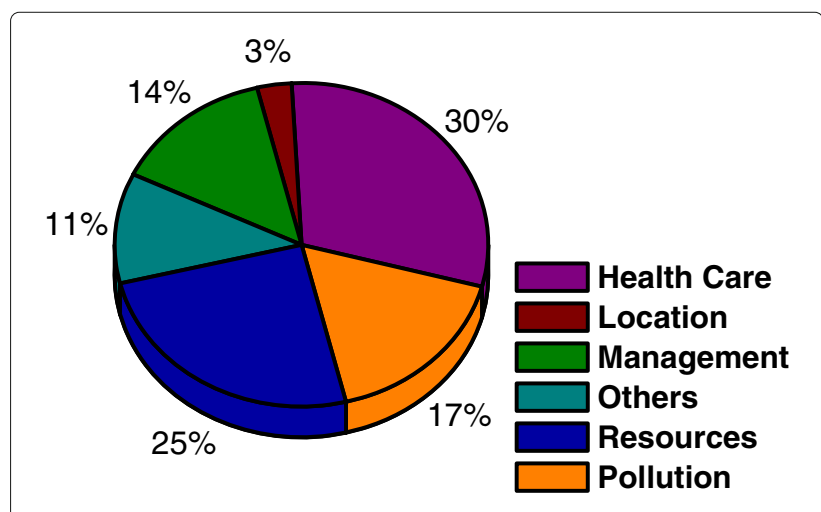

Fig. 4 Analysis of the types of intervention that are aided by the MCDA 
The Others class is the combination of the works that did not fit into the classes previously explained, deals with interventions related to the sorting of the best doctor for the family, the best teaching hospital, the identification of the risk levels in an emergency department, the criteria equity and efficiency of a health service, to verify that political values in health reflect the values of the population and to support the identification of highly disadvantaged areas, each occurring in each case.

\section{Definition of decision criteria}

The evaluation model, which conveys the results of the analysis of the consequences of an alternative, is usually too complex to be used directly in decision aid. Instead, one or more criteria should be developed to synthesize the relevant consequences, and be appropriate for the analysis of potential and deep comparisons between them [17]. Thus, knowing how DMs are deciding to set the criteria for decision problems becomes important.

The criteria used for decision found in the articles studied are shown in Fig. 5.

In 30 of the 66 articles studied in total (45\%) defined the criteria as basis in the literature. Of these articles, 23 used only the literature to define the criteria, 5 articles in addition to the literature also had support from experts and two other studies were supported by the literature together the DMs and people interested in the topic addressed by interviews.

The definition of criteria using only specialists was reported in $26 \%$ of the evaluated articles. In another hand the use of only discussion groups represented $21 \%$ of the total articles analyzed

At the criterion definition stage, only $8 \%$ of the papers had DMs as the main decision maker, this represents five articles.

\section{Some examples}

Examining the way in which health interventions are structured can help in formulating objectives and

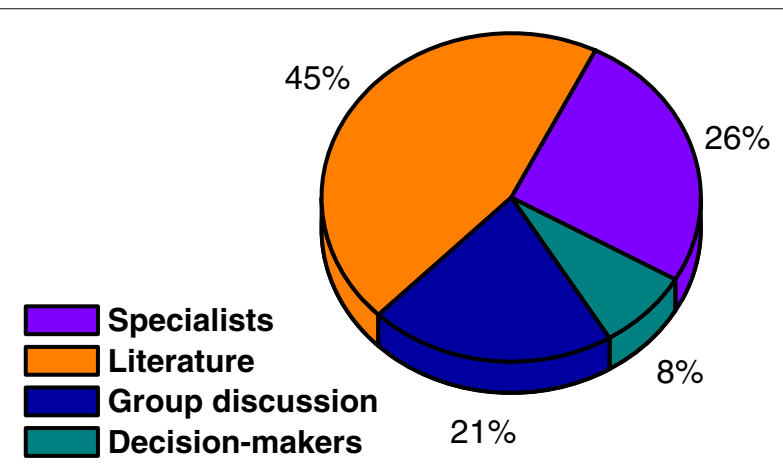

Fig. 5 Analysis of the strategy to define the criteria for structuring the MCDA determining the methodological steps of future work. Here some examples will be presented.

By whom, and how were the limits of the decision problems in the health area defined?

Decision makers - They presented the alternatives and parameters needed to structure the decision problem [21, 28];

Group decision - All participants gave the written consent form if they were willing to participate in the study. Two focus group discussions were conducted at a sixmonth interval. Recalling that the concerned parties had different origins [29];

Literature - The alternatives were structured according to MARKOV chains for medical gases and vacuum subsystems [30];

Specialist - the delimitation was the result of discussions with a specialist. The specialist assesses the needs and according to their knowledge and experience delimits the decision problem, formulating the objective and creating the alternatives [31, 32].

By whom, and how were the criteria identified?

Decision makers - The authors defined the four criteria to determine optimal patient management [33];

Group Decision - In order to generate an explicit model that helps stakeholders to reflect and analyze relevant issues more clearly, a facilitator is used who works impartially and helps those actors. As participants begin to work together, weighing the criteria and marking the topics, it is proven that this helps those involved to think and generate a comprehension and understanding of the problems, in a shared way [34];

Literature - Researching in the literature it is possible to verify that the economic, technical, environmental, and social criteria are elements used as selection criteria, in the process of evaluation of treatment alternatives. However, as there is a need to carry out a comprehensive evaluation regarding treatment alternatives, several authors point out that considering subcriteria related to the above mentioned criteria is an excellent way to perform these evaluations [35];

Specialists - The seven associated criteria and subcriteria have been adapted from the NHSIII to fit the United Arab Emirates public health system in the light of discussions with industry experts [36].

\section{Types of problem and multicriteria method}

To reach the proposed objective, the results referring to the type of intervention and multicriteria method are analyzed. The rationale for this research lies in the importance of the type of problematic to reflect on, the types of results that the analyst intends to achieve, how he sees himself in the process to help achieve those results and how he envisions his recommendations [17]. As well as the knowledge of which multi-criteria methods are most 
used, which aggregate the data into individual criteria to provide indicators of the overall performance of the alternatives [21].

As shown in Fig. 6a, the type of problematic of $47 \%$ of the included articles used the problematic of ranking, this represented 31 studies. The problem of choice was identified in $32 \%$ of the articles evaluated ( 21 articles) and the problem of sorting was finalized with 14 articles, or $21 \%$ of the total articles evaluated.

The analysis of multicriteria methods presents only those with more than one application, that is, those that were used in more than one article, so Fig. $6 \mathrm{~b}$ considers a total of 49 studies. AHP is the most representative method because it was used in 20 articles, representing almost $41 \%$ of the total. Following the FUZZY Logic, it represented $21 \%$ of the analyzed articles, followed by EVIDEM, ANP, MACBETH and TOPSIS (3 articles each), VIKOR and WHO-CHOICE are present in two studies each.

Figure 7 shows the type of problem versus the multicriteria method of included studies. Their analysis aims to visualize what methods researchers are choosing to help solve their decision problems. It is possible to observe that the eight highest occurrence methods of included studies are used in ranking problems. Also, that the AHP, the FUZZY Logic and the EVIDEM are used in the three different problems; TOPPIS and VIKOR in the issues of choice and ranking; The ANP and WHO-COHICE in the problematic of ranking and sorting; And the MACBETH in problems of choice.

In this section, the most representative information was presented, the characteristics of the other studies, as well as those presented in this text, are described in Table 1. These studies were the data used to present the panorama of MCDA publications in the highlighting its main characteristics and methodological steps.

\section{Exclusions}

The selected articles were analyzed under evaluation of the general questions and under specific questions focused on the methodological structure of the same. As for articles not approved in the screening process, which represented $70 \%$ of all articles read completely, were classified according to the types of irregularities found: no method, no criteria, not applied, out of subject, no application steps, and others (Fig. 8).

The criteria for exclusion of the articles of the present study were cataloged, with $34 \%$ of articles not having methods described in the text or not using MCDA. In 19\% of the articles excluded from the present study, there were no real applications, with only a descriptive of the problems to be treated. In $16 \%$ of the articles excluded, the criteria were not identified or were not explicitly stated. In these articles, the decision matrix were not developed, and in some cases, the description of the criteria does not exist.

Some studies analyzed fled the central theme, these being represented by $14 \%$ of the articles excluded. In these cases, the subjects did not involve the health area or, moreover, did not use the MCDA in general, $10 \%$ of the articles excluded from the present study were due to several other categories of exclusion presented in the methodology of this work. These categories include animal research and reviews that have gone unnoticed by screening. Finally, it was found that $7 \%$ of excluded articles did not follow the methodological structure with a whole.

In relation to the articles selected for study (30\% of articles read), in the scope of the general questions, the growth rate of the number of publications, the countries where they were applied, the author of the articles and the periodicals where they were published were evaluated. And from these data it was possible to determine not only a significant growth rate in the number of structured studies, but also the dissemination relation of this methodological structure of application.

\section{a Types of problem}

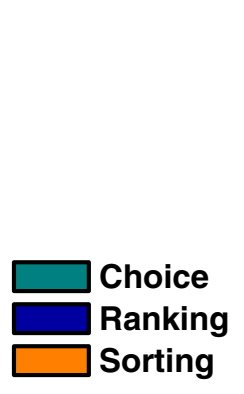

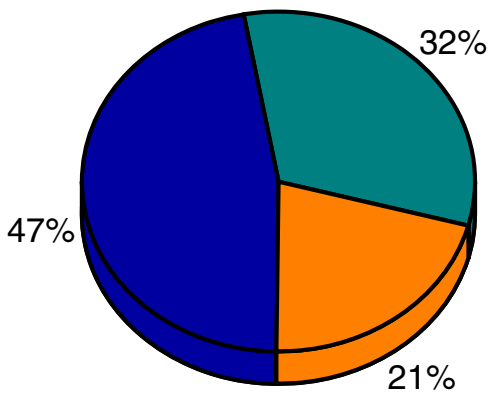

\section{b Methods type}

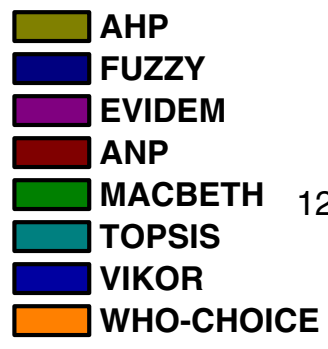

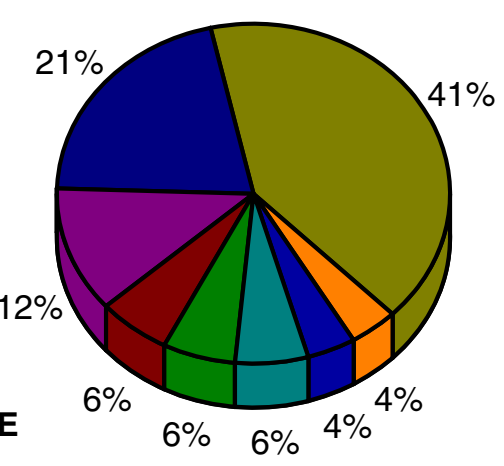

Fig. 6 Analysis of the problem and the main MCDAs methods used to aid decisions. a Types of problem. b Methods type 


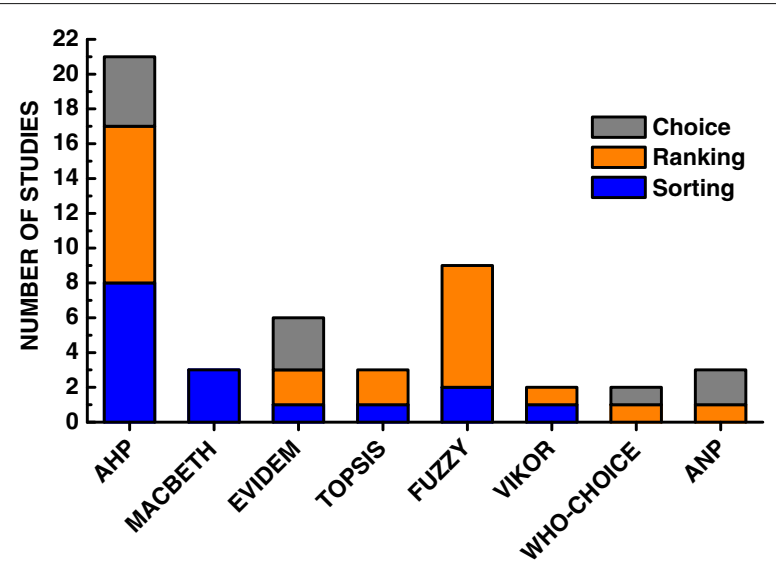

Fig. 7 Analysis of the MCDAs methods used to aid the decision of the problems of choice, ranking and sorting

Observing the lack of dominance in the aspects of the main authors and in the application sites, it can be assumed that the knowledge of the MCDA is undergoing an expansion in the range of health care, in other words, knowledge of the structured application of multicriteria is spreading and being applied and dominated by a wider range of scholars.

In the eligibility stage, 239 articles were included and only 66 selected. The analysis of exclusion reasons revealed that $21 \%$ of the articles do not make clear in their research the main methodological steps of the MCDA. And it is possible to apply the MCDA to help decision making in the health area, even without using a multicriteria method, but a purely mathematical model belonging to other areas of knowledge, such as Statistics [37].

\section{Discussion}

Compared to the figures found in Fig. 2a, we are able to affirm that between the 1990s and 2000, the growth of structured studies with a structured methodology was

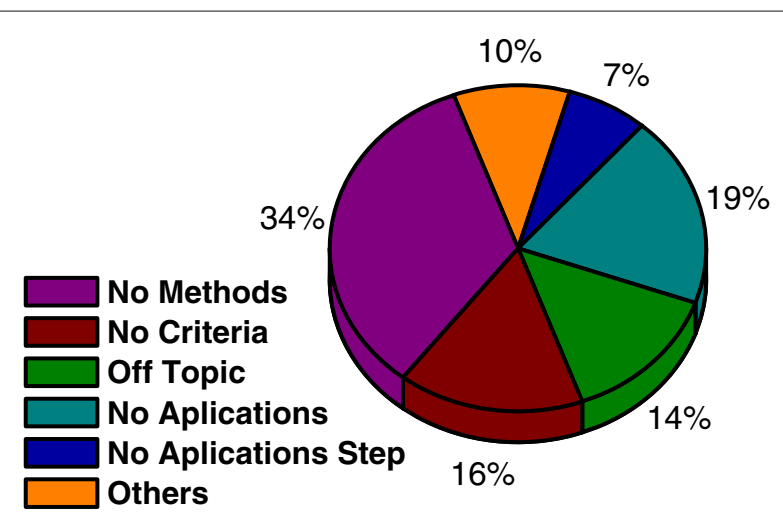

Fig. 8 Analysis of the number of articles excluded to reveal the main reasons for the exclusions
$450 \%(1990-1999=2$ publications, $2000-2009=9$ publications); $(2000-2009=9$ publications, $2010-2017$ $=55$ publications), with an increase of $611 \%$ Table 4 .

These data clearly indicate the growth of this type of study and the great importance that these researches have for the academic population over time. It also emphasizes the growing use of a structured methodology in the researches involving the subject, which strengthens and disseminates the MCDA.

In relation to the countries that most perform publications, Fig. 2b, we have a small dominance, since we have Canada [25, 29, 38-41]. Turkey [8, 31, 42-45] and USA [33, 46-50] with six publications each, followed by China [10, 51-54] and the Netherlands [21, 55-58] with five publications each, and Spain [28, 30, 59, 60] with four publications, with six countries accounting for $48 \%$ (thirty-two studies) of all publications by all thirty-three study countries.

On Fig. 2c, it can be said that the studies had fiftyeight different first authors, and that the group of seven authors shown in chart c, refers only to $23 \%$ of all publications (15 studies), while others Fifty-one authors with only one published article represent $77 \%$ of the research; thus affirming that there is no dominance of authors in the scenario studied.

In relation to the analysis of Fig. $2 \mathrm{~d}$, it can be seen that the nine journals analyzed in the graph represent a $30 \%$ share of all studies (20 articles), but since we have fifty-four journals with publications, this significant value can not be considered of dominance, and a homogeneous distribution is represented for the reference journals in the area.

In addition to the general data, issues related to the structuring and application of the multicriteria methodology were also analyzed. In Fig. 3 a small dominance is identified in the studies that use the literary questions to determine the research problem. In Fig. 4, the research objective is analyzed, it is clear that there is no dominance, but a highlight for two points, first research on the treatment of diseases (30\% of research) and allocation of resources (25\%). Figure 5 shows the methodology used to determine the criteria, and in this case, presented dominance of the literature (45\%). Figure 6a shows the division of the problems presented in the articles, highlighting those classified as ranking (47\%) and Fig. 6b shows the main methods used, especially AHP (41\%) and Fuzzy

Table 4 Growth analysis of the studies to indicate the growth of the structured articles with the structured methodology

\begin{tabular}{lll}
\hline Decade & Quantity & Growth \\
\hline 1990 & 2 & - \\
2000 & 9 & $450 \%$ \\
2010 & 55 & $611 \%$ \\
\hline
\end{tabular}


Logic (21\%). And Fig. 7 shows the relationship between the two previous data, identifying the correlation between the problem and the method used.

In addition, it is worth noting that in the literature investigated there are some trends and challenges that should be considered by those applying MCDA in health care. First, the criterion definition stage tends to happen more in tandem than the structuring of the problem. In the articles investigated, the percentage for all classes remains balanced, but when compared to the Decision-Makers class, it appears more in the structuring of the problem, but when it goes into the criteria definition phase, the tendency is for the process to occur participatory manner.

Second, even though it does not appear, data analysis is important, highlighting the role of the analyst, responsible for managing the entire decision process. Third, from the structuring and definition of the criteria of the decision problem, the analyst already has enough information to choose the best, or better methods for the construction of the multicriteria decision model. Fourth, in the studies analyzed there is a tendency for participatory processes. Fifth, the review shows that the greatest interest of all who use the MCDA to aid their decisions is after the resolution to visualize their alternatives as a ranking, proving one of the advantages of the MCDA, which is, in addition to saying what to do, it shows you how to do it.

This research was limited in two areas, purposely when the level of the journals used and the selection of research platforms were selected, and the acceptance of the only peer-reviewed articles; but also in a disproportionate way by the visualization of the articles, since some of the articles researched were not open.

\section{Conclusion}

The application of the MCDA methodology has been disseminated and applied around the world, and increasingly used in widely humanized areas such as health. The studies presented in this review are shown as indicators of the current scenario, exposing not only the importance of the MCDA, but also its methodological structure of application.

Regarding the general aspects of the studies, a growing trend was observed in the application of these methods, in addition to having no dominance in relation to the authors of the publication and the periodicals where they are published, but some countries stand out in terms of the number of published researches, such as such as Canada, Turkey and the USA.

In the definition of the problem of decision and stage of definition of the criteria, of studies included the literature presented the greatest demand for those who wish to structure their decision problem, however, it was verified that the literature added to group discursions showed good acceptance. Finally, it was verified by the analysis of the problematic, that the MCDA to solve problematic of Ranking has extensive application in the health area. As for the methods, the dominance of the AHP and FUZZY Logic was remarkable.

With this, it is possible to observe, through the data of this review, that more than the multicriteria methods, the multicriteria decision model has been highlighted, also in the health area. In addition, the study can guide new applications and techniques using MCDA in the health care.

For future work, the possibility of included studies focuses on descriptive researches, where mathematical methods are not used, aiming at the methodological application of the MCDA.

\section{Authors' contributions}

TDCF, DGGC and RPS conceived the study. TDCF and DGGC wrote and edited the manuscript. TDCF, DGGC and RPS participated in data collection and analysis. TDCF, DGGC, ELSC and RPS participated in interpretation of results. All authors read and approved the final manuscript.

Ethics approval and consent to participate Not applicable.

\section{Consent for publication}

Not applicable.

\section{Competing interests}

The authors declare that they have no competing interests.

\section{Publisher's Note}

Springer Nature remains neutral with regard to jurisdictional claims in published maps and institutional affiliations.

Received: 6 January 2018 Accepted: 27 September 2018

Published online: 01 November 2018

References

1. Kahraman C, Onar SC, Oztaysi B. Fuzzy Multicriteria Decision-Making: A Literature Review. Int J Comput Intell Syst. 2015;8(4):637-66. https://doi. org/10.1080/18756891.2015.1046325.

2. Tanios N, Wagner M, Tony M, Baltussen R, van Til J, Rindress D, Kind P, Goetghebeur MM. Which Criteria Are Considered in Healthcare Decisions? Insights From an International Survey of Policy and Clinical Decision Makers. Int J Technol Assess Health Care. 2013;29(4):456-65. https://doi.org/10.1017/S0266462313000573.

3. Keeney R L RH. Decisions with Multiple Objectives: Preferences and Value Tradeoffs. New York: Wiley; 1976.

4. Marsh K, Goetghebeur M, Thokala P BR. Multi-Criteria Decision Analysis to Support Healthcare Decisions. Switzerland AG: Springer; 2017.

5. Kaksalan M ZS, Wallenius J. Multiple Criteria Decision Making From Early History to the 21 st Century. Singapore: World Scientific Publishing Limited; 2011.

6. Youngkong S, Baltussen R, Tantivess S, Mohara A, Teerawattananon Y. Multicriteria Decision Analysis for Including Health Interventions in the Universal Health Coverage Benefit Package in Thailand. Value Health. 2012;15(6):961-70. https://doi.org/10.1016/j.jval.2012.06.006.

7. Thokala P, Devlin N, Marsh K, Baltussen R, Boysen M, Kalo Z, Longrenn T, Mussen F, Peacock S, Watkins J, Ijzerman M. Multiple criteria decision analysis for health care decision making - An introduction: Report 1 of the ISPOR MCDA Emerging Good Practices Task Force. Value Health. 2016;19(1):1-13. https://doi.org/10.1016/j.jval.2015.12.003.

8. Delice EK, Zegerek S. Ranking occupational risk levels of emergency departments using a new fuzzy MCDM model: A case study in Turkey. Appl Math Inf Sci. 2016;10(6):2345-56. https://doi.org/doi:10.18576/amis/ 100638.

9. Dehe B, Bamford D. Development, test and comparison of two Multiple Criteria Decision Analysis ( MCDA) models: A case of healthcare 
infrastructure location. Expert Syst Appl J. 2015;42:6717-27. https://doi. org/10.1016/j.eswa.2015.04.059.

10. Liu H-c, Wu J, Li P. Assessment of health-care waste disposal methods using a VIKOR-based fuzzy multi-criteria decision making method. Waste Manag. 2013;33:2744-51. https://doi.org/10.1016/j.wasman.2013.08.006.

11. Mühlbacher AC, Kaczynski A. Making Good Decisions in Healthcare with Multi-Criteria Decision Analysis: The Use, Current Research and Future Development of MCDA. Appl Health Econ Health Policy. 2016;14(1): 29-40. https://doi.org/10.1007/s40258-015-0203-4.

12. Gutknecht M, Schaarschmidt M-L, Herrlein O, Augustin M. A systematic review on methods used to evaluate patient preferences in psoriasis treatments. J Eur Acad Dermatol Venereol. 2016;30(9):1454-64. https:// doi.org/10.1111/jdv.13749.

13. Adunlin G, Diaby V, Xiao H. Application of multicriteria decision analysis in health care: A systematic review and bibliometric analysis. Health Expect. 2015;18(6):1894-905. https://doi.org/10.1111/hex.12287.

14. Marsh K, Lanitis T, Neasham D, Orfanos P, Caro J. Assessing the value of healthcare interventions using multi-criteria decision analysis: A review of the literature. PharmacoEconomics. 2014;32(4):345-65. https://doi.org/10. 1007/s40273-014-0135-0.

15. Almeida ADT. Processo de Decisão Nas Organizações: Construindo Modelos de Decisão Multicritério. São Pulo: Atlas: Editora UniversitÃiria, UFPE; 2013

16. Keeney RL, Raiffa H. Decisions with Multiple Objectives: Preferences and Value Tradeoffs. United Kingdom: Cambridge: Cambridge University Press; 1993.

17. Roy B. Multicriteria Methodology for Decision Aiding. US: Springer; 1996.

18. Bouyssou D, Marchant T, Pirlot M, Tsoukias A, Vincke P. Evaluation and Decision Models with Multiple Criteria Stepping Stones for the Analyst. US: Springer; 2006.

19. Wallenius J. Comparative Evaluation of Some Interactive Approaches to Multicriterion Optimization. Manag Sci. 1975;21(12):1387-96. https://doi. org $/ 10.1287 / \mathrm{mnsc} .21 .12 .1387$

20. Dolan J. Multi-Criteria clinical decision support: A Primer on the Use of Multiple-Criteria Decision-Making Methods to Promote Evidence-Based, Patient-Centered Healthcare. Patient: Patient-Centered Outcome Res. 2010;3:229-48.

21. Baltussen R, Niessen L. Priority setting of health interventions: the need for multi-criteria decision analysis. Cost Eff Resour Allocation. 2006;4(1):14. https://doi.org/10.1186/1478-7547-4-14.

22. Belton V ST. Multiple Criteria Decision: An I Ntegrated Approach. US: Springer; 2002.

23. Diaby V, Goeree R. How to use multi-criteria decision analysis methods for reimbursement decision-making in healthcare: a step-by-step guide. Expert Rev Pharmacoeconomics Outcomes Res. 2014;14(1):81-99. https://doi.org/10.1586/14737167.2014.859525.

24. Falagas ME, Zarkali A, Karageorgopoulos DE, Bardakas V, Mavros MN. The impact of article length on the number of future citations: $A$ bibliometric analysis of general medicine journals. PLOS ONE. 20131-8. https://doi.org/10.1371/journal.pone.0049476.

25. Goetghebeur MM, Wagner M, Khoury H, Levitt RJ, Erickson LJ, Rindress D. Evidence and Value : Impact on DecisionMaking and the EVIDEM framework and potential applications. BMC Health Serv Res. 2008;8(270): 1-16. https://doi.org/10.1186/1472-6963-8-270.

26. Lu MT, Lin SW, Tzeng GH. Improving RFID adoption in Taiwan's healthcare industry based on a DEMATEL technique with a hybrid MCDM model. Decis Support Syst. 2013;56(1):259-69. https://doi.org/10.1016/j. dss.2013.06.006

27. Doerner K, Focke A, Gutjahr WJ. Multicriteria tour planning for mobile healthcare facilities in a developing country. Eur J Oper Res. 2007;179: 1078-96. https://doi.org/10.1016/j.ejor.2005.10.067.

28. Carnero MC, Gómez A. A Multicriteria Model for Optimization of Maintenance in Thermal Energy Production Systems in Hospitals : A Case Study in a Spanish Hospital. Sustainability. 2017;9(493):1-41. https://doi. org/10.3390/su9040493.

29. Hongoh V, Michel P, Gosselin P, Samoura K, Ravel A, Campagna C, Cissé HD, Waaub JP. Multi-stakeholder decision aid for improved prioritization of the public health impact of climate sensitive infectious diseases. Int J Environ Res Public Health. 2016;13(4). https://doi.org/10. 3390/ijerph13040419.

30. Carnero MC. Fuzzy Multicriteria Model for Selection of Vibration Technology. Shock Vib. 20161-18. https://doi.org/doi:10.1155/2016/ 6723605.
31. Dursun M, Karsak EE, Karadayi MA. Fuzzy group decision making for the assessment of health-care waste disposal alternatives in Istanbul. World Acad Sci Eng Technol. 2010;66(6):1012-6.

32. Sustersic O, Rajkovic U, Dinevski D, Jereb E, Rajkovic V. Evaluating Patients' Health Using a Hierarchical Multi-attribute Decision Model. J Int Med Res. 2009;37(5):1646-54. https://doi.org/10.1177/ 147323000903700544.

33. Singh $\mathrm{S}$, Dolan JG, Centor RM. Optimal management of adults with pharyngitis-a multi-criteria decision analysis. BMC Med Inform Decis Mak. 2006;6:14. https://doi.org/10.1186/1472-6947-6-14.

34. Reddy BP, Kelly MP, Thokala P, Walters SJ, Duenas A. Prioritising public health guidance topics in the National Institute for Health and Care Excellence using the Analytic Hierarchy Process. Public Health. 2014;128(10):896-903. https://doi.org/10.1016/j.puhe.2014.07.003.

35. Padma T, Balasubramanie P. A fuzzy analytic hierarchy processing decision support system to analyze occupational menace forecasting the spawning of shoulder and neck pain. Expert Syst Appl. 2011;38(12): 15303-9. https://doi.org/10.1016/j.eswa.2011.06.037.

36. Hussain M, Malik M. Prioritizing lean management practices in public and private hospitals. J Health Organ Manag. 2016;30(3):457-74. https://doi. org/10.1108/JHOM-08-2014-0135.

37. Werner P. Israeli lay persons' views on priority-setting criteria for Alzheimer's disease. Health Expect. 2009;12(2):187-96. https://doi.org/10. 1111/j.1369-7625.2008.00523.x.

38. Diaby V, Lachaine J. An Application of a Proposed Framework for Formulary Listing in Low- income Countries: Case of Côte d' Ivoire. Appl Health Econ Health Policy. 2011;9(6):389-402. https://doi.org/10.2165/ 11595220-000000000-00000.

39. Goetghebeur MM, Wagner M, Khoury H, Rindress D, Grégoire J-p, Deal C. Combining multicriteria decision analysis, ethics and health technology assessment : applying the EVIDEM decisionmaking framework to growth hormone for Turner syndrome patients. Cost Eff Resour Allocation. 2010;8(4):1-15.

40. Tony $M$, Wagner $M$, Khoury $H$, Rindress $D$, Papastavros $T$, Oh $P$, Goetghebeur MM. Bridging health technology assessment (HTA) with multicriteria decision analyses (MCDA): field testing of the EVIDEM framework for coverage decisions by a public payer in Canada. BMC Healt h Serv Res. 2011;11(1):329. https://doi.org/10.1186/1472-6963-11-329.

41. Wagner M, Khoury H, Willet J, Rindress D, Goetghebeur M. Can the EVIDEM Framework Tackle Issues Raised by Evaluating Treatments for Rare Diseases: Analysis of Issues and Policies, and Context-Specific Adaptation. PharmacoEconomics. 2016;34(3):285-301. https://doi.org/10. 1007/s40273-015-0340-5.

42. Dursun M, Ertugrul Karsak E, Karadayi MA. A Fuzzy MCDM approach for health-care waste management. World Acad Sci Eng Technol. 2011;73(1): 858-64.

43. Dursun M, Karsak EE, Karadayi MA. Assessment of health-care waste treatment alternatives using fuzzy multi-criteria decision making approaches. Resour Conserv Recycl. 2011;57:98-107. https://doi.org/10. 1016/j.resconrec.2011.09.012.

44. Kulak $\mathrm{O}$, Goren $\mathrm{HG}$, Supciller AA. A new multi criteria decision making approach for medical imaging systems considering risk factors. Appl Soft Comput. 2015;35:931-41. https://doi.org/10.1016/j.asoc.2015.03.004.

45. Özkan A. Evaluation of healthcare waste treatment-disposal alternatives by using multi-criteria decision-making techniques. Waste Manag Res. 2013;31(2):141-9. https://doi.org/10.1177/0734242X12471578.

46. Diaby V, Sanogo V, Moussa KR. ELICIT: An alternative imprecise weight elicitation technique for use in multi-criteria decision analysis for healthcare. Expert Rev Pharmacoecon Outcomes Res. 2016;16(1):141-7. https://doi.org/10.1586/14737167.2015.1083863.ELICIT.

47. Diaz-Ledezma C, Lichstein PM, Dolan JG, Parvizi J. Diagnosis of Periprosthetic Joint Infection in Medicare Patients: Multicriteria Decision Analysis. Clin Orthop Relat Res. 2014;472(11):3275-84. https://doi.org/10. 1007/s11999-014-3492-2.

48. Dolan JG. Patient priorities in colorectal cancer screening decisions1. Health Expect. 2005;8(4):334-44. https://doi.org/10.1111/j.1369-7625. 2005.00348.x.

49. Kuzma J, Paradise J, Ramachandran G, Kim J-a, Kokotovich A, Wolf SM. An Integrated Approach to Oversight Assessment for Emerging Technologies. Risk Anal. 2008;28(5):1197-219. https://doi.org/10.1111/j. 1539-6924.2008.01086.x. 
50. Tarimcilar MM, Khaksari SZ. Capital budgeting in hospital management using the analytic hierarchy process. Socioecon Plann Sci. 1991;25(1):27-34.

51. Liu H-C, You J-x, Lu C, Shan M-m. Application of interval 2-tuple linguistic MULTIMOORA method for health-care waste treatment technology evaluation and selection. Waste Manag. 2014;34:2355-64.

52. Lu C, You J-X, Liu H-C, Li P. Health-Care Waste Treatment Technology Selection Using the Interval 2-Tuple Induced TOPSIS Method. Int J Environ Res Public Health. 2016;13(6):562. https://doi.org/10.3390/ ijerph13060562.

53. Paolucci F, Mentzakis E, Defechereux T, Niessen LW. Equity and efficiency preferences of health policy makers in China and a stated preference analysis. Health Policy Plan. 2015;30:1059-66. https://doi.org/ doi:10.1093/heapol/czu123.

54. Wang LE, Liu HC, Quan MY. Evaluating the risk of failure modes with a hybrid MCDM model under interval-valued intuitionistic fuzzy environments. Comput Ind Eng. 2016;102:175-85. https://doi.org/10. 1016/j.cie.2016.11.003

55. Graaf G, Postmus D, Buskens E. Using Multicriteria Decision Analysis to Support Research Priority Setting in Biomedical Translational Research Projects. BioMed Res Int. 2015;2015. https://doi.org/doi:10.1155/2015/ 191809.

56. Hummel JM, Steuten LGM, Groothuis-Oudshoorn CJM, Mulder N, ljzerman MJ. Preferences for colorectal cancer screening techniques and intention to attend: A multi-criteria decision analysis. Appl Health Econ He alth Policy. 2013;11(5):499-507. https://doi.org/10.1007/s40258-013-0051-z.

57. Til JV, Groothuis-oudshoorn C, Lieferink M, Dolan J, Goetghebeur M. Does technique matter; a pilot study exploring weighting techniques for a multi-criteria decision support framework. Cost Eff Resour Allocation. 2014;12(22):1-11.

58. Venhorst K, Zelle SG, Tromp N, Lauer JA. Multi-criteria decision analysis of breast cancer control in low- and middle- income countries : development of a rating tool for policy makers. Cost Eff Resour Allocation. 2014;12(13):1-10.

59. Rebolledo B, Gil A, Flotats X, Sánchez JA. Assessment of groundwater vulnerability to nitrates from agricultural sources using a GIS-compatible logic multicriteria model. J Environ Manag. 2016;171:70-80.

60. Wagner M, Khoury H, Bennetts L, Berto P, Ehreth J, Badia X, Goetghebeur M. Appraising the holistic value of Lenvatinib for radio-iodine refractory differentiated thyroid cancer: A multi-country study applying pragmatic MCDA. BMC Cancer. 2017;17(1):272. https://doi. org/10.1186/s12885-017-3258-9.

61. Jehu-appiah C, Baltussen R, Acquah C, Aikins M, Amah S, Bosu WK, Koolman X, Lauer J, Osei D, Adjei S. Balancing Equity and Efficiency in Health Priorities in Ghana : The Use of Multicriteria Decision Analysis. Int Soc Pharmacoeconomics Outcomes Res (ISPOR). 2008;11(7):1081-7.

62. Defechereux T, Paolucci F, Mirelman A, Youngkong S, Botten G, Hagen TP. Health care priority setting in Norway a multicriteria decision analysis. BMC Health Serv Res. 2012;12:39. https://doi.org/10.1186/1472-6963-12-39.

63. Mirelman A, Mentzakis E, Kinter E, Paolucci F, Fordham R, Ozawa S, Ferraz M, Baltussen R, Niessen LW. Decision-making criteria among national policymakers in five countries: A discrete choice experiment eliciting relative preferences for equity and efficiency. Value Health. 2012;15(3):534-9. https://doi.org/10.1016/j.jval.2012.04.001.

64. Sinuany-stern Z, Mehrez A, Tal A-g. The Location of a Hospital in a Rural Region : The Case of the Negev. Locat Sci. 1995;3(4):255-66.

65. Ahmadi H, Nilashi M, Ibrahim O. Organizational decision to adopt hospital information system: An empirical investigation in the case of Malaysian public hospitals. Int J Med Inform. 2015;84(3):166-88. https:// doi.org/10.1016/j.jmedinf.2014.12.004.

66. Ágnes G. Allocating resources for cancer control-resolving multicriteria decision-making using the analytic hierarchy process. US Oncol. 2007;51(3):197-208.

67. Danner M, Hummel JM, Volz F, van Manen JG, Wiegard B, Dintsios C-M, Bastian H, Gerber A, IJzerman MJ. Integrating patients' views into health technology assessment: Analytic hierarchy process (AHP) as a method to elicit patient preferences. Int J Technol Assess Health Care. 2011;27(04): 369-75. https://doi.org/10.1017/S0266462311000523.

68. Lee CW, Kwak NK. Strategic enterprise resource planning in a health-care system using a multicriteria decision-making model. J Med Syst. 2011;35(2):265-75. https://doi.org/10.1007/s10916-009-9362-x.
69. Isoke JB, Van Dijk MP. Factors influencing selection of drinking water technologies for urban informal settlements in Kampala. Water Environ J. 20131-18. https://doi.org/10.1111/wej.12058.

70. Oddershede AM, Cordova FM, Carrasco R, Watkins FJ. Decision Model for Assessing Healthcare ICT Support Implications : User Perception Healthcare ICT Network System Evaluation Approach The Analytic Hierarchy Process Methodology. Int J Comput Commun Control. 2014;9(5):593-601.

71. Stromme EM, Brienne K, Norheim OF. Disease Control Priorities for Neglected Tropical Diseases: Lessons from Priority Ranking Based on the Quality of Evidence, Cost Effectiveness, Severity of Disease, Catastrophic Health Expenditures, and Loss of Productivity. Dev World Bioeth. 2014;14(3):132-41. https://doi.org/10.1111/dewb.12016.

72. Cabrera-Barona P, Murphy T, Kienberger S, Blaschke T. A multi-criteria spatial deprivation index to support health inequality analyses. Int J Health Geogr. 2015;14(1):11. https://doi.org/10.1186/s12942-015-0004-X.

73. Kuruoglu E, Guldal D, Mevsim V, Gunvar T. Which family physician should I choose? The analytic hierarchy process approach for ranking of criteria in the selection of a family physician. BMC Med Inform Decis Mak. 2015;15(1):63. https://doi.org/10.1186/s12911-015-0183-1.

74. Ritrovato M, Faggiano FC, Tedesco G, Derrico P. Decision-Oriented Health Technology Assessment: One Step Forward in Supporting the Decision-Making Process in Hospitals. Value Health. 2015;18:505-11.

75. Wahlster $P$, Goetghebeur M, Schaller S, Kriza C, Kolominsky-rabas P. Exploring the perspectives and preferences for HTA across German healthcare stakeholders using a multi-criteria assessment of a pulmonary heart sensor as a case study. Health Res Pol Sys (2015). 201513-24. https://doi.org/10.1186/s12961-015-0011-1.

76. Carnero MC, Gómez A. A multicriteria decision making approach applied to improving maintenance policies in healthcare organizations. BMC Med Inform Decis Mak. 2016:16(1):47. https://doi.org/10.1186/s12911-016-0282-7.

77. Gómez A, Carnero MC. Decision Support System for maintenance policy optimization in medicinal gases subsystems. IFAC-PapersOnLine. 2016;49(28):268-73. https://doi.org/10.1016/j.ifacol.2016.11.046.

78. Hussain M, Malik M, Al Neyadi HS. AHP framework to assist lean deployment in Abu Dhabi public healthcare delivery system. Bus Process Manag J. 2016;22(3):546-65. https://doi.org/10.1108/BPMJ-08-2014-0074.

79. Kalhor R, Kiaei MZ, Mohebbifar R, Shah Bahrami E, Mafi L, Kalhor L, Azmal M. Prioritizing the options for health-care waste management in qazvin: Using a multi-criteria decision making approach. J Biol Today's World. 2016;5(6):101-6. https://doi.org/10.15412/J.JBTW.01050603.

80. Kim S, Kim S. A multi-criteria approach toward discovering killer loT application in Korea. Technol Forecast Soc Chang. 2016;102:143-55.

81. Mahfoud H, El Barkany A, El Biyaali A. A hybrid decision-making model for maintenance prioritization in health care systems. Am J Appl Sci. 2016;13(4):439-50. https://doi.org/10.3844/ajassp.2016.439.450

82. Merola E, Padoano E, Zuliani V. An analytic hierarchy process-based framework to support outsourcing decisions on hospital sterilisation. Int J Bus Sys Res. 2016;10(2-4):142-61. https://doi.org/10.1504/IJBSR.2016. 075747.

83. Mohamadi E, Tabatabaei SM, Olyaeemanesh A, Sagha SF, Davari M, Arabloo J, Yousefvand M, Mobinizadeh M. Coverage Decision-Making for Orthopedics Interventions in the Health Transformation Program in Iran: A Multiple Criteria Decision Analysis (MCDA). Shiraz E-Med J. 2016;17(2): 1-9. https://doi.org/10.17795/semj40920.Research.

84. Nilashi M, Ahmadi H, Ahani A, Ravangard R. Technological Forecasting \& Social Change Determining the importance of Hospital Information System adoption factors using Fuzzy Analytic Network Process ( ANP). Technol Forecast Soc Chang. 2016;111:244-64. https://doi.org/10.1016/j. techfore.2016.07.008.

85. Shafii M, Rafiei S, Abooee F, Bahrami MA, Nouhi M, Lotfi F, Khanjankhani K. Assessment of Service Quality in Teaching Hospitals of Yazd University of Medical Sciences: Using Multi-criteria Decision Making Techniques. Osong Public Health Res Perspect. 2016;7(4). https://doi.org/ 10.1016/j.phrp.2016.05.001.

86. Hancerliogullari G, Hancerliogullari KO, Koksalmis E. The use of multi-criteria decision making models in evaluating anesthesia method options in circumcision surgery. BMC Med Inform Decis Mak. 2017;17(1): 14. https://doi.org/10.1186/s12911-017-0409-5.

87. Hillerman T, Souza JCF, Reis ACB, Carvalho RN. Applying clustering and AHP methods for evaluating suspect healthcare claims. J Comput Sci. 2017;19:97-111. https://doi.org/10.1016/j.jocs.2017.02.007. 